\title{
Prolyl Hydroxylase Domain 2 Protein Is a Strong Prognostic Marker in Human Gastric Cancer
}

\author{
Carsten Kamphues $^{\mathrm{a}}$ Daniel Wittschieber ${ }^{\mathrm{b}}$ Frederick Klauschen ${ }^{\mathrm{b}}$ \\ Atsuko Kasajima $^{b}$ Manfred Dietel ${ }^{b}$ Sven-Christian Schmidt ${ }^{a}$ \\ Matthias Glanemann ${ }^{a}$ Marcus Bahra ${ }^{a}$ Peter Neuhaus ${ }^{a}$ Wilko Weichert ${ }^{c}$ \\ Albrecht Stenzinger ${ }^{c}$ \\ ${ }^{a}$ Department of General, Visceral and Transplantation Surgery, and ${ }^{b}$ Institute of Pathology, Charité University \\ Hospital, Berlin, and 'Institute of Pathology, Heidelberg University Hospital, Heidelberg, Germany
}

\section{Key Words}

EGL nine homolog 1 - Prolyl hydroxylase domain 2 protein • Gastric cancer • Angiogenesis • Hypoxia-inducible factor

\begin{abstract}
Objective: According to recent research, prolyl hydroxylase domain 2 protein (PHD2) plays an important role in human carcinogenesis by inducing neovascularization and tumor growth. The aim of this study was to evaluate PHD2 expression patterns in primary gastric adenocarcinoma and to test for a potential predictive value of PHD2 expression in gastric cancer patients. Methods: In a total of 121 patients, PHD2 expression was investigated by immunohistochemistry in paraffin-embedded tissue and correlated with clinicopathological parameters and patient survival. Results: 64 of 121 gastric carcinomas (52.9\%) showed PHD2 expression in tumor cell cytoplasm. In univariate analysis, PHD2-negative patients had a significantly shortened survival in comparison with PHD2-postive patients (19.5 vs. 32.7 months, $p=0.02$ ). Independent prognostic significance could be shown in multivariate analysis for PHD2 expression ( $p=0.005)$, age at diagnosis $(p=0.012)$, lymph node status $(p=0.016)$ and $R$
\end{abstract}

status ( $p=0.026$ ). Conclusion: Cytoplasmic PHD2 expression has a strong impact on survival in gastric cancer patients. Therefore, PHD2 represents a useful predictive biomarker in the evaluation of high-risk patients. Furthermore, these results underline the importance of PHD2 in gastric carcinogenesis and may identify PHD2 as a putative target for future gastric cancer therapy.

Copyright $\odot 2012$ S. Karger AG, Basel

\section{Introduction}

Despite a declining incidence over the past 20 years, gastric cancer still represents one of the most common cancer types in the Western world [1-3]. According to recent cancer statistics, gastric cancer is the fourth most common malignancy in the world and accounts for $10.4 \%$ of cancer deaths, which makes this entity the second leading cause of cancer-related deaths worldwide [1-3].

To date, the standard treatment for gastric cancer is surgery [3-5]. Although there are many controversies about various aspects of surgical management, such as the extent of resection, the extent of lymphadenectomy or

\section{KARGER}

Fax +4161306 1234 E-Mail karger@karger.ch www.karger.com
(C) 2012 S. Karger AG, Basel

1015-2008/12/0791-0011\$38.00/0

Accessible online at:

www.karger.com/pat
Carsten Kamphues, MD

Department of General, Visceral and Transplantation Surgery

Charité, University Medicine, Campus Virchow Clinic

Augustenburger Platz 1, DE-13353 Berlin (Germany)

Tel. +4930450652 208, E-Mail carsten.kamphues@ charite.de 
the role of laparoscopic surgery $[3,6,7]$, radical resection of the tumor remains the only curative treatment option for gastric cancer. However, since more than $50 \%$ of the patients receiving potentially curative resection relapse and a large number of patients present at an advanced stage of disease, systemic chemotherapy and radiotherapy are also part of a multimodality treatment concept. Despite this, the prognosis of patients suffering from gastric cancer is still poor, reaching 5-year survival rates of $62 \%$ for patients with localized disease, but only $22 \%$ for patients with positive lymph nodes and $3 \%$ when the tumor has spread to distant organ sites [2]. Although many efforts are being made in order to improve the efficacy of chemotherapy, a considerable number of patients still display chemoresistance and usually die within 1 year due to tumor progression [3].

Based on these facts, it becomes obvious that new therapeutic options are urgently needed in order to improve patient survival. Furthermore, new predictive markers may be useful in the evaluation of high-risk patients.

Evidence has accumulated showing that prolyl hydroxylase domain 2 protein [PHD2; alternative name for EGL nine homolog 1 (EGLN1)] plays an important role in the vascularization of solid tumors and carcinogenesis [8]. Because of their rapid growth, most solid tumors exhibit areas of hypoxia due to a high rate of cellular proliferation and limited blood supply. Therefore, tumor cells must be able to adapt to hypoxia by inducing neovascularization. Recent studies have shown that PHD2 represents one of the key oxygen sensors in this process $[9,10]$. In the presence of oxygen, PHD2 hydroxylates a subunit of hypoxia-inducible factor 1 (HIF1), which plays an important role in the development of a variety of cancers [11, 12]. After hydroxylation, HIF is able to interact with von Hippel-Lindau E3 ubiquitin ligase, a well-known tumor suppressor. This leads to the degradation of HIF and inhibits the transcription of proangiogenic factors. Conversely, in case of hypoxia, $\mathrm{PHD} 2$ remains inactive; as a consequence, HIF cannot interact with Hippel-Lindau E3 ubiquitin ligase and becomes transcriptionally active, resulting in the promotion of angiogenesis. Furthermore, HIF-mediated transcription also regulates many processes in cellular homeostasis, including anaerobic metabolism and oxygen-carrying capacity $[13,14]$.

Although the role of PHD2 in tumorigenesis is still under discussion, several groups have recently shown that a shortage of PHD2 in tumor cells in vitro and in vivo leads to a dramatic enhancement of tumor growth [1518]. Therefore, it appears that agents activating PHD2 in tumor cells may provide novel therapeutic options in cancer patients.

The aim of the present study was to evaluate the cytoplasmic expression patterns of PHD2 in primary gastric adenocarcinoma. Furthermore, we investigated the link between PHD2 expression and clinicopathological data, including patient survival, in order to test for a potential predictive value of PHD2 expression in gastric carcinoma patients and to identify patients who might be suitable for novel target therapies.

\section{Methods}

Between 1996 and 2002, a total of 121 consecutive patients who underwent complete or partial gastrectomy due to histologically confirmed gastric cancer at our center were enrolled in this study. The gastrectomy was performed according to the standard guidelines on the treatment of gastric cancer [3]. Patients were excluded in case of presurgically treated cancer, recurrent gastric cancer or other malignancies. Furthermore, according to the guidelines, none of the patients received adjuvant or palliative chemotherapy after resection of the primary gastric carcinoma. Ninety-seven out of all patients had complete medical files until the end of the follow-up period and could therefore participate in the survival analysis.

Demographic and survival data of all patients were collected in a prospective database. Gastric cancer was histologically classified according to Lauren and staged according to the TNM guidelines (version 6). All patients in the study gave their written informed consent for the use of their tissues according to the Declaration of Helsinki.

\section{Analysis of Cytoplasmic PHD2 Expression in Gastric Cancer}

Tissue

The cytoplasmic expression of PHD2 in tumor tissue was analyzed by immunohistochemistry. Formalin-fixed paraffin-embedded tissue specimens were cut freshly $(5 \mu \mathrm{m})$. The sections were mounted on superfrost slides (Menzel Gläser, Braunschweig, Germany), dewaxed with xylene and gradually hydrated. Antigen retrieval was achieved by pressure cooking in $0.01 \mathrm{M}$ citrate buffer for $5 \mathrm{~min}$. Slides were incubated with an established polyclonal PHD2 anti-rabbit antibody (NB100-137; Novus Biologicals, Littleton, Colo., USA) [19, 20] diluted 1:4,000 in background reducing dilution buffer (Zymed, San Francisco, Calif., USA) at room temperature for $1 \mathrm{~h}$. Detection took place according to the manufacturer's instructions using a streptavidin-biotin system (BioGenex, San Ramon, Calif., USA) with alkaline phosphatase as the reporting enzyme. Either diaminobenzidine chromogen (Dako, Germany) or Fast-red (Sigma-Aldrich, Munich, Germany) served as chromogen. Slides were then briefly counterstained with hematoxylin and mounted using Aquatex (Merck, Gernsheim, Germany). Omission of the primary antibody served as negative control.

All tissue slides were evaluated independently by two expert pathologists of our center (A.S. and D.W.). To account for differences in staining, a semiquantitative immunoreactivity scoring system (IRS) was applied. To obtain the IRS, staining intensity 
$(0=$ no staining, $1=$ weak staining, $2=$ moderate staining, $3=$ strong staining) as well as the percentage of cells stained $(0=$ no cells, $1=<10 \%$ of cells, $2=11-50 \%$ of cells, $3=51-80 \%$ of cells, $4=>81 \%$ of cells) were evaluated for each patient and the respective scores were multiplied, resulting in an IRS range of $0-12$. For statistical analysis, cases were grouped as either PHD2 positive (IRS 7-12) or PHD2 negative (IRS 0-6). The widely used IRS cutoff value was defined prior to the evaluation of immunostaining and statistical data analysis $[21,22]$.

\section{Statistical Analysis}

Statistical analysis was performed using SPSS 17.0 for Windows (SPSS Inc., Chicago, Ill., USA) and the R (version 2.8.1, GNU/Linux) statistical software. All quantitative data were expressed as means and standard error of the mean (SEM), unless otherwise indicated. Fisher's exact test and the $\chi^{2}$ test were used for the assessment of a statistically significant correlation between PHD2 expression and clinicopathological parameters. Univariate survival analysis was performed according to Kaplan-Meier, significant differences in survival curves were evaluated using the log-rank test. Multivariate survival analysis was undertaken with Cox's regression model. A p value of less than $5 \%$ was regarded as statistically significant.

\section{Results}

\section{Demographics and Pathological Parameters}

The study population consisted of 68 male (56.2\%) and 53 female (43.8\%) patients who underwent gastric resection at our center for a histologically confirmed gastric cancer. Nearly $90 \%$ of the tumors were histologically classified as T2 or T3 and although more than $84 \%$ of the tumors showed lymphatic invasion, metastases could only be detected in 14 patients (11.6\%). Detailed data on histological classification and staging of the tumors are summarized in table 1 .

Ninety-seven of these patients had complete medical files during the follow-up period and could therefore be included in the survival analysis. After a mean follow-up period of 18.3 months (SD 5.3 months), 31 of these patients $(31.9 \%)$ were still alive reaching a mean overall survival of 28.6 months (SD 3.19 months).

\section{Cytoplasmic PHD2 Expression in Gastric}

\section{Adenocarcinoma and Correlation between PHD2}

Expression and Clinicopathological Parameters

In 64 of 121 gastric carcinomas (52.9\%), immunohistochemistry showed PHD2 expression in the tumor cell cytoplasm. Normal gastric mucosa displayed focal weak to moderate cytoplasmic immunostaining of the gastric glands. The surface epithelium was found to be PHD2 negative (fig. 1). A strong correlation was found between
Table 1. Overall cytoplasmic PHD2 expression and correlation to selected clinicopathological parameters in patients with gastric adenocarcinoma (Fisher's exact test and $\chi^{2}$ test)

\begin{tabular}{|c|c|c|c|c|}
\hline Characteristics & $\begin{array}{l}\text { All } \\
\text { cases }\end{array}$ & $\begin{array}{l}\text { PHD2 } \\
\text { negative }\end{array}$ & $\begin{array}{l}\text { PHD2 } \\
\text { positive }\end{array}$ & $\begin{array}{l}\mathrm{p} \\
\text { value }\end{array}$ \\
\hline All cases & 121 & $57(47.1 \%)$ & $64(52.9 \%)$ & \\
\hline \multicolumn{5}{|l|}{ Age at diagnosis } \\
\hline$\leq 65$ years & $66(54.5 \%)$ & $35(53.0 \%)$ & $31(47.0 \%)$ & \multirow{2}{*}{0.201} \\
\hline$>65$ years & $55(45.5 \%)$ & $22(40.0 \%)$ & $33(60.0 \%)$ & \\
\hline \multicolumn{5}{|l|}{ Tumor stage } \\
\hline $\mathrm{T} 1$ & $6(5.0 \%)$ & $4(66.7 \%)$ & $2(33.3 \%)$ & \multirow{4}{*}{0.718} \\
\hline $\mathrm{T} 2$ & $52(43.0 \%)$ & $22(42.3 \%)$ & $30(57.7 \%)$ & \\
\hline T3 & $55(45.5 \%)$ & $26(47.3 .0 \%)$ & $29(52.7 \%)$ & \\
\hline $\mathrm{T} 4$ & $8(6.6 \%)$ & $5(62.5 \%)$ & $3(37.5 \%)$ & \\
\hline \multicolumn{5}{|c|}{ Lymph node status } \\
\hline N0 & $25(20.7 \%)$ & $10(71.0 \%)$ & $15(29.0 \%)$ & \multirow{4}{*}{0.229} \\
\hline N1 & $42(34.7 \%)$ & $18(42.9 \%)$ & $24(57.1 \%)$ & \\
\hline $\mathrm{N} 2$ & $39(32.2 \%)$ & $21(53.8 \%)$ & $18(46.2 \%)$ & \\
\hline N3 & $15(12.4 \%)$ & $8(53.3 \%)$ & $7(46.7 \%)$ & \\
\hline \multicolumn{5}{|c|}{ State of metastasis } \\
\hline M0 & $107(88.4 \%)$ & $48(44.9 \%)$ & $59(55.1 \%)$ & \multirow{2}{*}{0.255} \\
\hline M1 & $14(11.6 \%)$ & $9(64.3 \%)$ & $5(35.7 \%)$ & \\
\hline \multicolumn{5}{|l|}{ R status } \\
\hline R0 & $92(76.0 \%)$ & $42(45.6 \%)$ & $50(54.6 \%)$ & \multirow{2}{*}{0.670} \\
\hline $\mathrm{R} 1$ & $29(24.0 \%)$ & $15(51.7 \%)$ & $14(48.3 \%)$ & \\
\hline \multicolumn{5}{|c|}{ Lauren classfication } \\
\hline Intestinal & $65(53.7 \%)$ & $21(32.3 \%)$ & $15(31.9 \%)$ & \multirow{3}{*}{0.001} \\
\hline Diffuse & $47(38.8 \%)$ & $32(56.1 \%)$ & $15(31.9 \%)$ & \\
\hline Mixed & $9(7.4 \%)$ & $4(44.4 \%)$ & $5(55.6 \%)$ & \\
\hline \multicolumn{5}{|l|}{ Grade } \\
\hline G1 & $2(1.7 \%)$ & $2(100.0 \%)$ & $0(00.0 \%)$ & \multirow{3}{*}{0.167} \\
\hline $\mathrm{G} 2$ & $27(22.3 \%)$ & $7(25.9 \%)$ & $20(74.1 \%)$ & \\
\hline G3 & $92(76.0 \%)$ & $48(52.2 \%)$ & $44(47.8 \%)$ & \\
\hline \multicolumn{5}{|c|}{ Tumor localization } \\
\hline Cardia & $36(29.8 \%)$ & $16(44.4 \%)$ & $20(55.6 \%)$ & \multirow{4}{*}{0.076} \\
\hline Corpus & $43(35.5 \%)$ & $18(41.9 .9 \%)$ & $25(58.1 \%)$ & \\
\hline Antrum & $38(31.4 \%)$ & $23(60.5 \%)$ & $15(39.5 \%)$ & \\
\hline Fundus & $4(3.3 \%)$ & $0(0.0 \%)$ & $4(100.0 \%)$ & \\
\hline
\end{tabular}

PHD2 expression and tumor growth pattern according to the Lauren classification, showing that intestinal tumors were more likely to express PHD2 than diffuse or mixed tumors ( $p=0.001$ ) (fig. 2). No correlation existed between PHD2 expression and any other clinicopathological parameter listed in table 1. Nor could a link be established between PHD2 expression and tumor localization ( $\mathrm{p}=$ $0.076)$.

\section{Impact of Cytoplasmic PHD2 Expression and} Clinicopathological Parameters on Patient Survival

In univariate analysis, the following conventional prognostic factors had a statistically significant impact 
Table 2. Univariate survival analysis for cytoplasmic PHD2 expression and selected clinicopathological parameters

\begin{tabular}{|c|c|c|c|c|c|}
\hline & \multirow[t]{2}{*}{ Cases } & \multirow[t]{2}{*}{ Events } & \multicolumn{2}{|c|}{ Survival months } & \multirow{2}{*}{$\begin{array}{l}\text { log-rank } \\
\text { test } \\
\text { (p value) }\end{array}$} \\
\hline & & & mean & SEM & \\
\hline \multicolumn{6}{|c|}{ Age at diagnosis } \\
\hline$\leq 65$ years & 52 & 33 & 33.580 & 4.486 & \multirow{2}{*}{0.036} \\
\hline$>65$ years & 45 & 35 & 21.347 & 3.722 & \\
\hline \multicolumn{6}{|l|}{ Tumor stage } \\
\hline $\mathrm{T} 1$ & 3 & 1 & 57.533 & 8.764 & \multirow{4}{*}{0.034} \\
\hline $\mathrm{T} 2$ & 44 & 27 & 35.420 & 4.916 & \\
\hline $\mathrm{T} 3$ & 44 & 35 & 11.233 & 3.615 & \\
\hline T4 & 6 & 5 & 11.233 & 4.320 & \\
\hline \multicolumn{6}{|c|}{ Lymph node status } \\
\hline N0 & 19 & 12 & 37.714 & 7.228 & \multirow{4}{*}{0.021} \\
\hline N1 & 36 & 24 & 30.425 & 4.647 & \\
\hline $\mathrm{N} 2$ & 29 & 22 & 18.654 & 3.179 & \\
\hline N3 & 13 & 10 & 12.137 & 5.102 & \\
\hline \multicolumn{6}{|c|}{ State of metastasis } \\
\hline M0 & 86 & 60 & 29.206 & 3.393 & \multirow{2}{*}{0.401} \\
\hline M1 & 11 & 8 & 15.561 & 4.299 & \\
\hline \multicolumn{6}{|l|}{$\mathrm{R}$ status } \\
\hline R0 & 73 & 47 & 33.033 & 3.895 & \multirow{2}{*}{0.016} \\
\hline $\mathrm{R} 1$ & 24 & 21 & 16.739 & 4.306 & \\
\hline \multicolumn{6}{|c|}{ Lauren classification } \\
\hline Intestinal & 52 & 34 & 32.768 & 4.540 & \multirow{3}{*}{0.634} \\
\hline Diffuse & 38 & 28 & 17.908 & 2.470 & \\
\hline Mixed & 7 & 6 & 26.419 & 10.588 & \\
\hline \multicolumn{6}{|l|}{ Grade } \\
\hline G1 & 1 & 0 & not & not & \multirow{3}{*}{0.430} \\
\hline G2 & 23 & 16 & $\begin{array}{l}\text { reached } \\
30.749\end{array}$ & $\begin{array}{l}\text { reached } \\
3.156\end{array}$ & \\
\hline G3 & 73 & 52 & 25.438 & 3.178 & \\
\hline \multicolumn{6}{|c|}{ Tumor localization } \\
\hline Cardia & 28 & 19 & 30.949 & 5.789 & \multirow{4}{*}{0.343} \\
\hline Corpus & 35 & 23 & 29.314 & 4.963 & \\
\hline Antrum & 31 & 23 & 24.108 & 4.502 & \\
\hline Fundus & 3 & 3 & 7.411 & 5.082 & \\
\hline \multicolumn{6}{|c|}{ PHD2 expression } \\
\hline Negative & 45 & 36 & 19.527 & 3.795 & \multirow[b]{2}{*}{0.020} \\
\hline Positive & 52 & 32 & 32.733 & 4.048 & \\
\hline
\end{tabular}

$\mathrm{p}<0.05$ is considered as significant; significant $\mathrm{p}$ values are shown in bold.

on patient survival: age at diagnosis $(\mathrm{p}=0.036)$, tumor stage $(p=0.034)$, lymph node status $(p=0.021)$ and $R$ status $(p=0.016)$. Furthermore, we could establish a statistically significant influence of PHD2 expression on patient survival by log-rank testing $(\mathrm{p}=0.020)$ (table 2$)$. PHD2negative patients had a significantly shorter survival compared with PHD2-positive patients (19.5 vs. 32.7 months) (fig. 3).

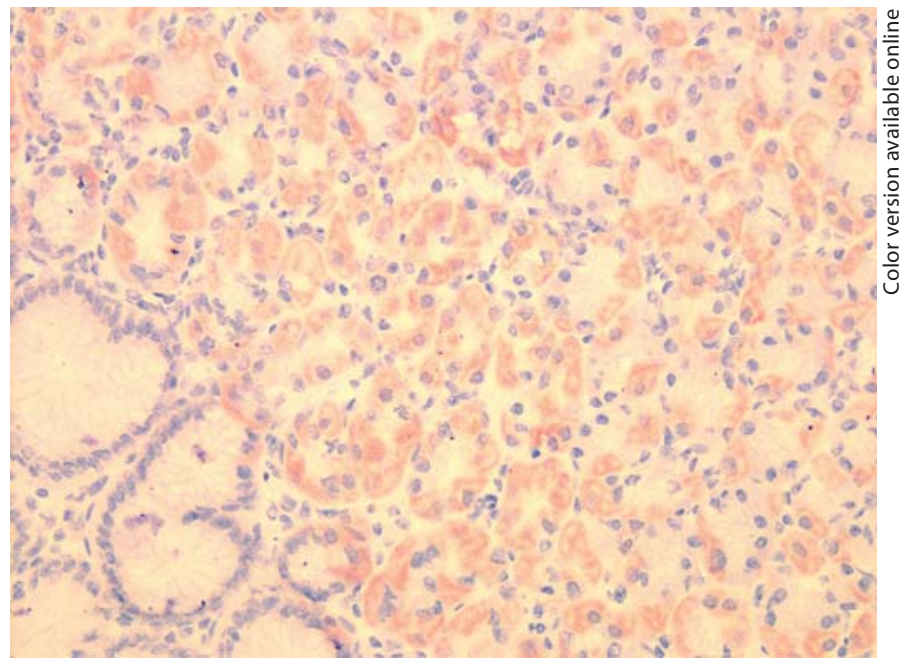

Fig. 1. PHD2 expression in normal gastric mucosa $(\times 20)$. Gastric glands beneath the surface epithelium focally display weak to moderate cytoplasmic PHD2 expression. Expression of PHD2 is absent in surface and foveolar epithelium.
Multivariate survival analysis (Cox regression model) including age at diagnosis, tumor stage, lymph node status, R status and PHD2 expression did not reveal an independent statistically significant impact of tumor stage on patient survival $(\mathrm{p}=0.230)$. In contrast, age at diagnosis $(\mathrm{p}=0.012)$, lymph node status $(\mathrm{p}=0.016)$ and $\mathrm{R}$ status $(\mathrm{p}=0.026)$ as well as cytoplasmic PHD2 expression ( $\mathrm{p}=$ 0.005 ) showed independent prognostic significance, with PHD2 expression being the strongest predictive marker for patient survival (table 3).

\section{Discussion}

Due to wide variation in the prognosis of patients with gastric carcinomas, the evaluation of high-risk patients by reliable predictive markers has become more and more important in recent years. Conventional prognostic markers were investigated in several studies showing a high predictive value especially of histological parameters like tumor stage and lymph node status $[3,4]$. These results are supported by the present study in which a strong predictive effect was found for tumor stage, nodal positivity as well as $\mathrm{R}$ status and age at diagnosis in univariate analysis. In contrast, tumor localization and classification (according to Lauren) had no impact on patient survival. 
Fig. 2. PHD2 expression in gastric adenocarcinoma tissue. a, c Strong cytoplasmic expression of PHD2 was observed in intestinal-type gastric carcinoma tissue $(\mathbf{a} \times 10$, c $\times 20)$. b, d Weak or absent staining in diffuse-type carcinomas $(\mathbf{b} \times 10, \mathbf{d} \times 20)$.
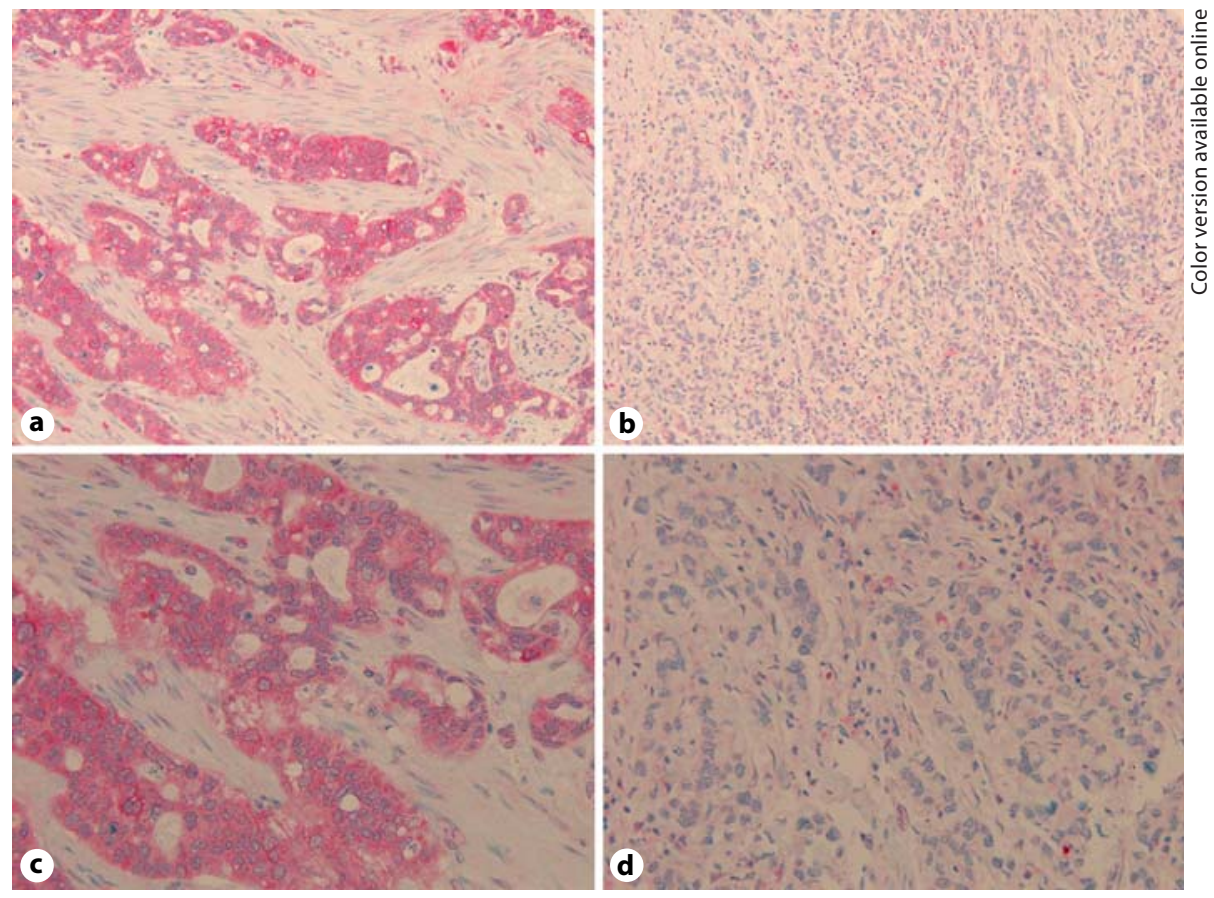

Since the identification of high-risk patients by reliable predictive markers is essential in the treatment of cancer patients, an increasing number of studies have recently focused on the expression of regulatory enzymes that play important roles in the development of cancer cells $[21,22$,$] . In addition to their usefulness as biomarkers,$ these enzymes may also be potential targets for novel therapies [23]. In this context, several studies examined the expression patterns of PHD2, an oxygen sensor that controls cellular response to hypoxic stress by interacting with HIF1. In one of the first studies, Kato et al. [16] showed that a high mutation rate of PHD2 with subsequent underexpression was associated with rapid tumor growth and a poor prognosis in patients with endometrial carcinomas. Similar results were presented by Lee et al. [15] in 2006. In a lineage of cell strains with varying transforming characteristics, PHD2 protein levels were inversely correlated with tumor-forming potential. Another study by Chan et al. [17] hypothesizes that silencing of PHD2 might promote angiogenesis and tumor growth, which was investigated by comparing normal colonic tissue and colon carcinoma tissue. The same study group also showed that silenced PHD2 in human colorectal cancer cell lines leads to tumor progression in vivo [18]. The authors could not explain the fact that silencing of PHD2 did not affect tumor growth in vitro, but their observation suggests that the effect of PHD2 in human

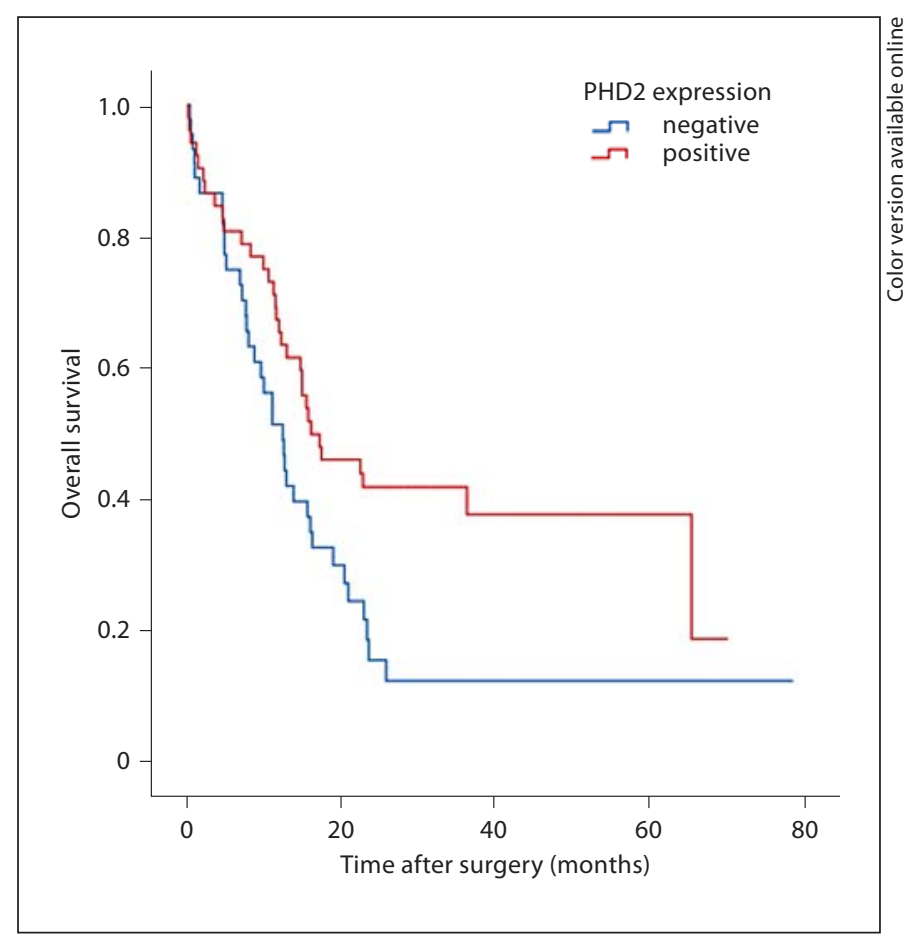

Fig. 3. Kaplan-Meier curves depicting overall survival according to PHD2 expression patterns. 
Table 3. Multivariate survival analysis for PHD2 expression and selected clinicopathological parameters using the Cox regression model

\begin{tabular}{|c|c|c|c|}
\hline & \multicolumn{3}{|c|}{ Overall survival } \\
\hline & HR & $95 \% \mathrm{CI}$ & $\mathrm{p}$ value \\
\hline \multicolumn{3}{|l|}{ Age at diagnosis } & 0.012 \\
\hline$\leq 65$ years & 0.532 & $0.325-0.871$ & \\
\hline$>65$ years & referent & & \\
\hline \multicolumn{3}{|l|}{ Lymph node status } & 0.016 \\
\hline No & 0.255 & $0.105-0.621$ & \\
\hline N1 & 0.336 & $0.156-0.725$ & \\
\hline $\mathrm{N} 2$ & 0.402 & $0.181-0.895$ & \\
\hline N3 & referent & & \\
\hline \multicolumn{3}{|l|}{ R status } & 0.026 \\
\hline R0 & 0.547 & $0.322-0.930$ & \\
\hline $\mathrm{R} 1$ & referent & & \\
\hline \multicolumn{3}{|l|}{ PHD2-expression } & 0.005 \\
\hline Negative & 2.070 & $1.247-3.439$ & \\
\hline Positive & referent & & \\
\hline \multicolumn{4}{|l|}{ Not significant } \\
\hline Tumor stage & & & 0.230 \\
\hline
\end{tabular}

tumorigenesis is more complex and requires further studies.

To our knowledge, the present study is the first to evaluate the expression patterns of cytoplasmic PHD2 in human gastric carcinoma. We demonstrated that loss of expression of PHD2 is strongly correlated with poor patient survival. In multivariate analysis, PHD2 turned out to be the strongest prognostic factor for patient survival which led to the conclusion that cytoplasmic PHD2 expression may serve as a reliable prognostic immunohistochemical biomarker in gastric adenocarcinoma in the future.

Besides the usefulness of the evaluation of cytoplasmic PHD2 expression in the identification of high-risk patients, our results might also lead to the development of novel drugs targeting PHD2 function. Although the effects of PHD2 on tumor growth are still under discussion and the observed statistical effects of PHD2 expression on prognosis do not necessarily imply functional relevance, several studies revealed that drugs known to interfere with PHD2 expression might become therapeutically valuable in the future, especially when combined with other antiangiogenesis drugs.

Durczak et al. [2], for instance, showed that apicidin, a selective histone deacetylase 2 and 3 inhibitor, upregulates PHD2 transcript levels in several cervical cancer cell lines. Another activator of PHD2 was found by Choi et al. [25]. Activation of PHD2 by a new drug, KRH 102053, leads to a decrease in HIF1 levels in vitro, resulting in a downregulation of HIF-regulated downstream target genes, such as vascular endothelial growth factor and aldolase A. Although the upregulation of cytoplasmic PHD2 in tumor cells is hoped to lead to reduced tumor growth, animal models suitable to further study these important questions are still lacking. In a recently published study, it could be demonstrated that an increase in PHD2 expression by an orally active endothelin B receptor antagonist reduced tumor growth and neovascularization in nude mice bearing melanoma xenografts [26, 27]. Since our data indicate an essential role of PHD 2 in tumorigenesis of gastric cancer, these studies suggest that activation of PHD2 might represent a promising novel target therapy and might lead to a prolongation of survival in gastric cancer patients. Additionally, besides the effect of PHD2 on tumor growth, it could be shown by Brökers et al. [28] that PHD2 inhibition in tumor cells may lead to increased chemoresistance. How this result can be used in the treatment of gastric cancer should also be an aspect of further research.

Elucidation of the bivalent role of PHD2 in tumor and endothelial cells represents another challenge. In contrast to the reports on PHD2 expression in tumor cells, Mazzone et al. [29] reported that inhibition of PHD2 in endothelial cells leads to normalization of the endothelial barrier, resulting in improved tumor oxygenation and prolonged survival. They showed that in PHD2-haplodeficient mice, reduced endothelial PHD2 expression did not affect tumor growth but prevented metastases by stabilization of tumor vessels. With respect to future tumor therapies, the question whether selective inhibition of endothelial PHD2 can be combined with activation of tumor cell PHD2 remains challenging.

\section{Conclusions}

In conclusion, we present the first study showing that cytoplasmic PHD2 is a strong prognostic biomarker for gastric adenocarcinoma that might be useful in identifying high-risk patients. Since PHD2 plays an important role in tumorigenesis, PHD2 might represent a potential target for chemotherapy in gastric cancer patients in the future. However, there is an urgent need of further studies in order to improve our understanding of the role of PHD2 in gastric carcinogenesis and to evaluate possible therapeutic options evolving from these findings. 


\section{References}

$\checkmark 1$ Kobayashi T, Kikuchi S, Lin Y, Yagyu K, Obata Y, Ogihara A, et al: Trends in the incidence of gastric cancer in Japan and the associations with Helicobacter pylori infection and gastric mucosal atrophy. Gastric Cancer 2004;7:233-239.

$\checkmark 2$ Jemal A, Siegel R, Ward E, Hao Y, Xu J, Murray $\mathrm{T}$, et al: Cancer statistics, 2008. CA Cancer J Clin 2008;58:71-96.

$\checkmark 3$ Alberts SR, Cervantes A, van de Velde CJ: Gastric Cancer: epidemiology, pathology and treatment. Ann Oncol 2003;14:2:31-36.

$\checkmark 4$ Shi Y, Zhou Y: The role of surgery in the treatment of gastric cancer. J Surg Oncol 2010;101:687-692.

5 D'souza MA, Singh K, Shrikhande SV: Surgery for gastric cancer: an evidence-based perspective. J Can Res Ther 2009;5:225-231.

-6 Sasako M, Sano T, Yamamoto S, Kurokawa Y, Nashimoto A, Kurita A, et al: D2 lymphadenectomy alone or with para-aortic nodal dissection for gastric cancer. N Engl J Med 2008;359:453-462.

7 Strong VE, Devaud N, Allen PJ, Gonen M, Brennan MF, Coit D: Laparoscopic versus open subtotal gastrectomy for adenocarcinoma: a case-control study. Ann Surg Oncol 2009;16:1507-1513.

$>8$ Fong GH, Takeda K: Role and regulation of prolyl hydroxylase domain proteins. Cell Death Differ 2008;15:635-641.

-9 Bruick RK, McKnight SL: A conserved family of prolyl-4-hydroxylases that modify HIF. Science 2001;294:1337-1340.

$\checkmark 10$ Berra E, Benizri E, Ginouves A, Volmat V, Roux D, Pouyssegur J: HIF prolyl-hydroxylase 2 is the key oxygen sensor setting low steady-state levels of HIF- $1 \alpha$ in normoxia. EMBO J 2003;22:4082-4090.
1 Zhong H, De Marzo AM, Laughner E, Lim M, Hilton DA, Zagzag D, et al: Overexpression of hypoxia-inducible factor $1 \alpha$ in common human cancers and their metastases. Cancer Res 1999;59:5830-5835.

12 Semenza GL: HIF-1 and tumor progression: pathophysiology and therapeutics. Trends Mol Med 2002;8:62-67.

13 Carmeliet P, Jain RK: Angiogenesis in cancer and other disease. Nature 2000;407:249-257.

14 Semenza GL: Targeting HIF-1 for cancer therapy. Nature 2003;3:721-731.

15 Lee KA, Lynd JD, O’Reilly S, Kiupel M, McCormick JJ, LaPres JJ: The biphasic role of the hypoxia-inducible factor prolyl-4-hydroxylase, PHD2, in modulating tumorforming potential. Mol Cancer Res 2008;6: 829-842.

16 Kato H, Inoue T, Asanoma K, Nishimura C, Matsuda T, Wake N: Induction of human endometrial cancer cell senescence through modulation of HIF-1 $\alpha$ activity by EGLN1. Int J Cancer 2006;118:1144-1153.

17 Chan DA, Kawahara TL, Sutphin PD, Chang HY, Chi JT, Giaccia AJ: Tumor vasculature is regulated by $\mathrm{PHD} 2$-mediated angiogenesis and bone marrow-derived cell recruitment. Cancer Cell 2009;15:527-538.

18 Chan DA, Giaccia AJ: PHD2 in tumor angiogenesis. Br J Cancer 2010;1:1-5.

19 Vogel S, Wottawa M, Farhat K, Zieseniss A, Schnelle M, Lee-Huu S, et al: Prolyl hydroxylase domain (PHD) 2 affects cell migration and F-actin formation RhoA/rho-associated kinase-dependent cofilin phosphorylation. J Biol Chem 2010;285:33756-33763.

20 Jokilehto T, Rantanen K, Luukkaa M, Heikkinen P, Grenman R, Minn H, et al: Overexpression and nuclear translocation of hypoxia-inducible factor prolyl hydroxylase PHD2 in head and neck squamous cell carcinoma is associated with tumor aggressiveness. Clin Cancer Res 2006;12:1080-1087.
21 Weichert W, Röske A, Gekeler V, Beckers T, Ebert MP, Pross M, et al: Association of patterns of class I histone deacetylase expression with patient prognosis in gastric cancer: a retrospective analysis. Lancet Oncol 2008; 9:139-148.

$\checkmark 22$ Weichert W, Ullrich A, Schmidt M, Gekeler V, Noske A, Niesporek S, et al: Expression patterns of polo-like kinase 1 in human gastric cancer. Cancer Sci 2006;97:271-276.

23 Jain RK: A New Target for Tumor Therapy. N Engl J Med 2009;360:269-271.

24 Durczak M, Jagodzinski PP: Apicidin upregulates PHD2 prolyl hydroxylase gene expression in cervical cancer cells. Anti Cancer Drugs 2010;21:619-624.

25 Choi HJ, Song BJ, Gong YD, Gwak WJ, Soh Y: Rapid degradation of hypoxia-inducible factor-1 $\alpha$ by KRH102053, a new activator of prolyl hydroxylase 2. Br J Pharmacol 2008; 154:114-125.

26 Spinella F, Rosano L, Di Castro V, Decandia S, Nicotra MR, Natali PG, et al: Endothelin-1 and endothelin-3 promote invasive behaviour via hypoxia-inducible factor- $1 \alpha$ in human melanoma cells. Cancer Res 2007;67: 1725-1734.

27 Spinella F, Rosano L, Del Duca M, Di Castro V, Nicotra MR, Natali PG, et al: Endothelin-1 inhibits prolyl hydroxylase domain 2 to activate hypoxia-inducible factor- $1 \alpha$ in melanoma cells. PLoS 2010;5:e11241.

28 Brökers N, Le-Huu S, Vogel S, Hagos Y, Katschinski DM, Kleinschmidt M: Increased chemoresistance induced by inhibition of HIF-prolyl-hydroxylase domain enzymes. Cancer Sci 2010;101:129-136.

-29 Mazzone M, Dettori D, Leite de Oliveira R, Loges S, Schmidt T, Jonckx B, et al: Heterozygous deficiency of PHD2 restores tumor oxygenation and inhibits metastasis via endothelial normalization. Cell 2009;136:839851. 